\title{
Effect of Age and Level of Cognitive Function on Spontaneous and Exploratory Behaviors in the Beagle Dog
}

\author{
Christina T. Siwak, ${ }^{1}$ P. Dwight Tapp, ${ }^{2}$ and Norton W. Milgram ${ }^{1,2,3}$ \\ ${ }^{1}$ Institute of Medical Science, ${ }^{2}$ Department of Psychology, University of Toronto, Scarborough, Ontario, Canada, M1C 1A4
}

\begin{abstract}
Cognitively characterized young and aged beagle dogs were administered six different spontaneous behavior tests, which provided measures of locomotion, exploration, and social interaction. Consistent with our previous findings, we obtained no overall effect of age on locomotion. We did find, however, that for the aged dogs locomotion correlated with level of cognitive function, being lowest in age-unimpaired dogs and highest in impaired dogs. Exploratory behavior, as measured by response to novelty, varied with age, with young dogs scoring the highest. Young dogs spent more time with novel toys and a person, responded more to a silhouette of a dog, and interacted more with a model dog compared to aged dogs. Among the aged dogs, age-unimpaired dogs spent the greatest amount of time sitting or standing beside a person whereas age-impaired dogs spent the most time reacting to a reflection in a mirror. The age-impaired dogs show undirected, stereotypical types of behavioral patterns. These differences in activity patterns may be linked to underlying age-associated neuropathology.
\end{abstract}

Cognitive deficits in aging have been studied extensively in a wide range of species. Typically, however, the variability among aged animals within a species is extensive, and only a limited number show marked behavioral deficits (Ingram 1988; Gallagher and Burwell 1989). Several reports have identified two subgroups of aged animals; one group whose performance on a variety of behavioral tests does not differ from that of young animals and a second group whose performance is dramatically worse compared to young animals (Gallagher and Burwell 1989; Rowe et al. 1998; Adams et al. 2000b). Other aspects of behavior are also affected by age, and these may be independent of cognition (Gage et al. 1984). Age-related deficits on simple tests of motor function (wire-grip test, bridge crossing, locomotor activity, sensorimotor reactivity) were unrelated to impairments in spatial learning using the Morris water maze (Gage et al. 1984).

Gallagher and Burwell (1989), however, reported that performance on other behavioral tasks (i.e., recovery from neophobia) coincided with spatial learning ability in the Morris water maze. Rowe et al. (1998) also found that cognitively impaired and unimpaired aged rats could be discriminated on the basis of behavioral measures distinct from those assessing learning and memory. Impaired animals were less responsive to novel stimuli and exhibited a deficit in habituation to an aversive stimulus.

The majority of this research has used rodent models.

${ }^{3}$ Corresponding author.

E-MAIL milgram@psych.utoronto.ca; FAX (416) 287-7642.

Article and publication are at http://www.learnmem.org/cgi/doi/ 10.1101/lm.41701.
The present experiment sought to extend these findings to a higher-level species, the dog (Canis familiaris). Dogs and humans share similar cardiopulmonary systems, environmental influences, and brain pathology, and studies using the dog may prove valuable to discern the underlying causes of age-associated ailments in both species (Cummings et al. 1996). We were particularly interested in a possible relationship between behavioral activity, exploratory behavior, and neuropsychological measures of cognitive function in aged dogs.

Exploratory behavior has previously been considered to be a kind of instinctive behavior, necessary for survival. However, researchers now regard exploration to be a highlevel aspect of sensory processing involved in investigating novel stimuli (Kelley et al. 1989). A novel environment or novel objects in a familiar environment offer opportunities to learn and explore (Pierce and Courchesne 2001). Exploration generally involves movement or locomotor activity, but locomotion includes behaviors such as spontaneous activity, exercise, or escape that are unrelated to exploration (Archer and Birke 1983). Berlyne (1960) distinguished between specific and diversive exploration. Specific exploration is activity directed towards obtaining selective information, whereas diversive exploration is a more general motor activity elicited by a wide range of internal and external stimuli. Exploratory behavior is likely dependent on intact prefrontal cortical-striatal-pallidal circuitry as well as cerebellar function (Pierce and Courchesne 2001).

One method of studying exploration is with the use of the open field, which involves characterizing an animals'

LEARNING \& MEMORY 8:317-325 @ 2001 by Cold Spring Harbor Laboratory Press ISSN1072-0502/01 \$5.00

$$
\begin{array}{lllllllllllllll} 
& E & A & R & N & I & N & G & \mathcal{Q} & M & E & M & O & R & Y \\
\text { www.learnmem.org } & & &
\end{array}
$$


behavior in a standardized environmental chamber. However, the open field test cannot distinguish locomotion per se from stimulus-directed exploratory behavior because of the absence of specific external stimuli (Brennan et al. 1982). In fact, several studies have shown that locomotor activity and exploration can be dissociated. Montgomery (1953) concluded that exploration is independent from general activity when activity deprivation did not lead to an increase in exploratory behavior. Leyland et al. (1976) showed that novel and complex stimulation increased exploration but did not affect locomotor activity in rats. The correlation between the two types of behaviors was close to zero. Finally, amphetamine selectively increases locomotion but decreases exploration (Leyland et al. 1976).

Test situations in which discrete stimuli are present and distinguishable from the general background provide a more appropriate means of studying exploration. Berlyne $(1950,1955)$ noted that approaches to specific items provide a more informative measure of exploration than nonspecific approaches to areas in the environment.

Exploratory behavior, independent of locomotion, has been found to decline with age in rodents (Furchgott et al. 1961; Williams et al. 1966; Brennan et al. 1982; Handa et al. 1996). In the past we have used locomotor activity as a measure of exploration in dogs. We previously reported that locomotion in the open field is not significantly affected by age in canines (Head and Milgram 1992; Head et al. 1997). The present study attempts to distinguish between exploratory locomotion and stimulus directed exploration and is concerned with the effects of aging on exploratory behavior in beagle dogs. We also sought to study the effect of age on the presence of both artificial conspecifics and people. Accordingly, we developed five novel protocols to provide indices of exploratory and social behaviors. We hypothesized that exploratory behavior would be related to level of cognitive function. Accordingly, we divided the aged dogs into cognitively impaired and unimpaired, based on neuropsychological tests of cognitive function.

\section{RESULTS}

\section{Cognitive Characterization}

The aged dogs were classified as cognitively impaired or unimpaired based on their performance on the delayed nonmatching to position (DNMP) task at 10-, 20-, and 30-sec delays and on a size discrimination learning task. The combined error score for both tasks was compared to that of the young dog group. An aged dog was considered impaired if its score was greater than two standard deviations from the mean of the young dog group. An aged dog with a score less than two standard deviations from the mean of the young dogs was placed in the unimpaired group. The mean score and standard deviation for the young dog group was $80 \pm 59.49$. Any aged dog with a score greater than 198.98 was classified as impaired. The distribution of error scores for the combined error score and the ages of the dogs are illustrated in Figure 1. The age-unimpaired group consisted of six males and five females. The age-impaired group had two males and $10 \mathrm{fe}-$ males. The correlation between performance on the DNMP and size discrimination tasks was 0.32 .

\section{Open Field Test}

A comparison of the old and young dogs' locomotion, without taking into account cognitive status, revealed no significant difference $[\mathrm{F}(1,26)=1.69, P=0.20]$ (Fig. 2). Significant main effects of age $[\mathrm{F}(1,26)=10.11, P=0.0038]$ and $\operatorname{sex}[\mathrm{F}(1,26)=21.62, P=0.000085]$ were obtained for urination frequency. The interaction between age and sex was also significant $[\mathrm{F}(1,26)=18.97, P=0.00018]$. Young males urinated significantly more often than young females $(P=0.00026)$, old females $(P=0.00018)$, and old males $(P=0.00022)$. A main effect of retest on sniffing frequency was obtained $[\mathrm{F}(1,26)=7.14, P=0.013]$. Sniffing frequency increased from open field test 1 to open field test 2 . A significant interaction between sex and retest revealed that sniffing frequency increased in the females only $[\mathrm{F}(1,26)=17.25, P=0.00031]$. The interaction between age, sex and retest was also significant $[\mathrm{F}(1,26)=7.77$, $P=0.0098$ ], indicating that sniffing frequency increased in young females from open field test 1 to open field test 2 .

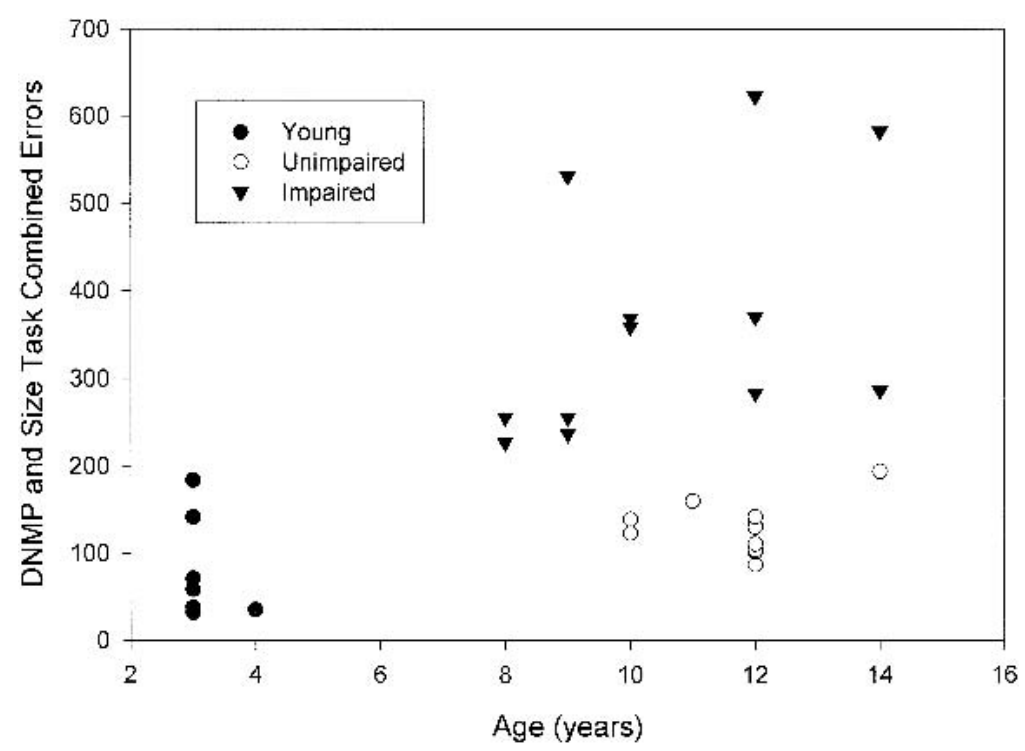

Figure 1 The combined sum of errors required to learn a delayed nonmatching to position task and a size discrimination learning task are plotted as a function of age and presence or absence of cognitive impairment.

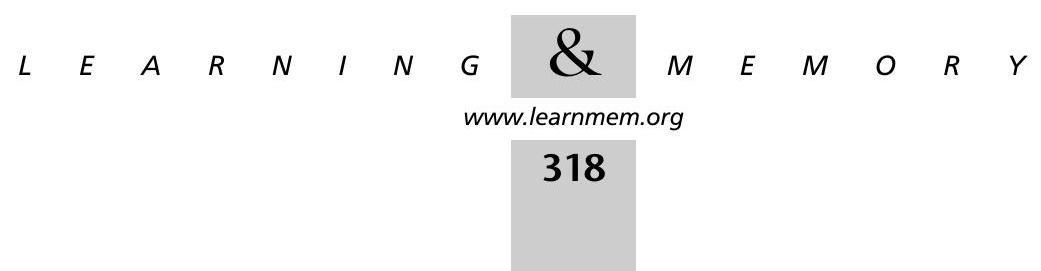



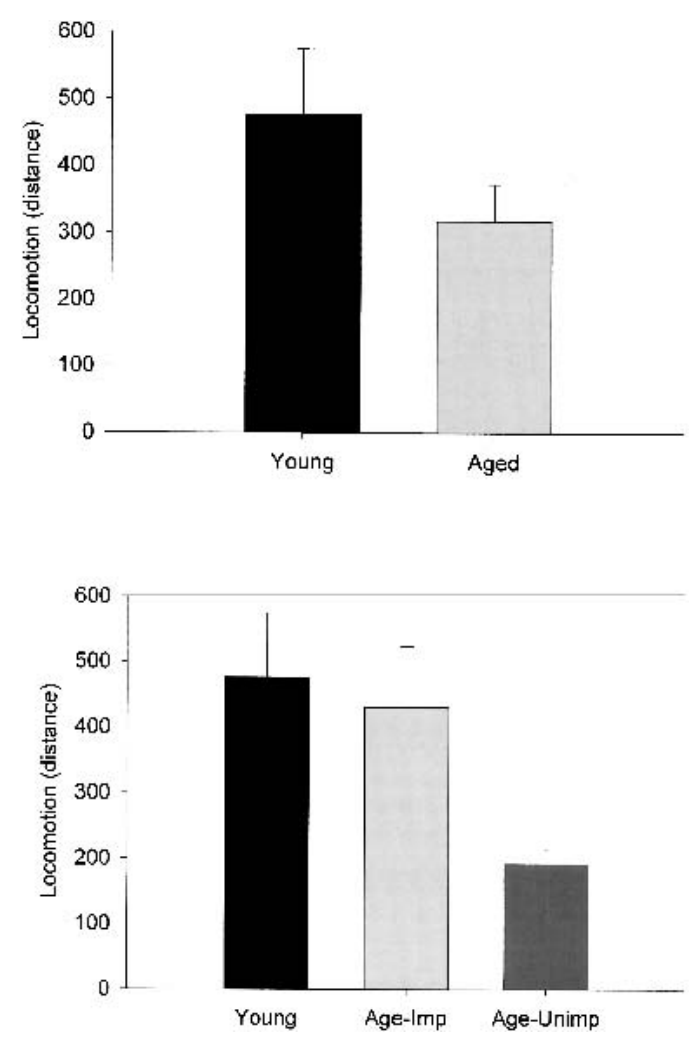

Figure 2 Locomotion in an open field for young, age-unimpaired and age-impaired groups. There is no difference between young and aged dogs in locomotion unless cognitive status is taken into account. The age-unimpaired dogs showed lower levels of locomotion than the young $(P=0.058)$ and age-impaired $(P=0.067)$ groups. Error bars represent standard errors of the mean.

The analysis of time spent inactive also revealed a significant main effect of age $[\mathrm{F}(1,26)=5.31, P=0.029]$. Aged dogs spent more time inactive than young dogs.

When the aged dogs were subdivided into impaired and unimpaired, the ANOVA revealed a significant main effect of group $[\mathrm{F}(2,27)=3.89 ; P=0.033]$ on locomotion (Fig. 2). The age-unimpaired dogs showed less locomotion than the young $(P=0.058)$ and age-impaired $(P=0.067)$ groups.

\section{Mirror Test}

The ANOVA revealed a significant main effect of retest $[\mathrm{F}(1,26)=16.48, P=0.0004]$ for frequency of sniffing the mirror reflection. Sniffing frequency decreased from mirror test 1 to mirror test 2 .

When the analysis considered cognitive status, significant main effects of group $[\mathrm{F}(2,27)=4.32, P=0.024]$ and retest $[\mathrm{F}(1,27)=5.16, P=0.031]$ appeared for the amount of time spent interacting with the mirror reflection. As shown in Figure 3, the age-impaired dogs spent significantly more time interacting with the reflection than the age-un- impaired dogs $(P=0.018)$. Interaction time decreased from test 1 to test 2 .

\section{Human Interaction Test}

The analysis of the amount of time spent in physical contact with the person revealed significant main effects of age $[\mathrm{F}(1,26)=7.64, P=0.010]$ and retest $[\mathrm{F}(1,26)=10.35$, $P=0.0034]$. Young dogs spent more time in contact with the person than old dogs, and contact time decreased from human interaction test 1 to test 2 . The interaction between age and retest was significant $[\mathrm{F}(1,26)=7.36, P=0.012]$, indicating that contact time decreased for the young dogs only from test 1 to test 2 , whereas the aged dogs showed no change. The three-way interaction between age, retest, and sex was also significant $[\mathrm{F}(1,26)=4.51, P=0.043]$. Contact time decreased from human interaction test 1 to test 2 in the young female dogs.

The analysis of time spent beside the person revealed a significant main effect of age $[\mathrm{F}(1,26)=4.59, P=0.042]$ and an age by sex interaction $[\mathrm{F}(1,26)=4.45, P=0.045]$. Aged males spent significantly more time beside the person than young males $(P=0.025)$ and aged females $(P=0.017)$. No significant effects were obtained for the frequency of sniffing the person in the room.

Cognitive status affected the responses of the dogs to the person. The analysis of the amount of time spent in physical contact with the person revealed significant main effects of group $[\mathrm{F}(2,27)=4.23, P=0.025]$ and retest $[\mathrm{F}(1,27)=5.094, P=0.032]$. The young dogs spent more time in contact with the person than the age-unimpaired $(P=0.050)$ and the age-impaired $(P=0.029)$ groups.

The analysis of the amount of time that the dogs spent sitting or standing beside the person revealed a significant main effect of group $[\mathrm{F}(2,27)=6.71, P=0.0043]$. The age-

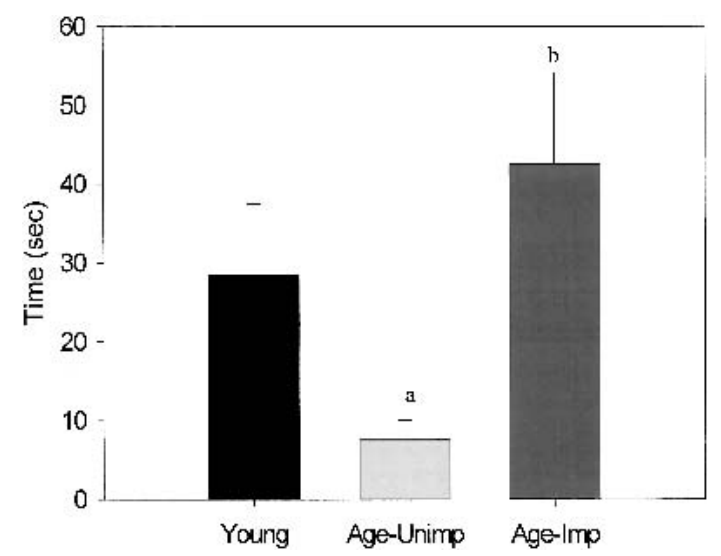

Figure 3 Time in seconds that dogs spent interacting with their reflection in the mirror. Age-impaired dogs spent significantly more time interacting with a mirror reflection than age-unimpaired $(P=0.018)$ dogs. The young dogs were intermediate between the two age groups. "a" is significantly different from " $b$ ". Error bars represent standard errors of the mean.

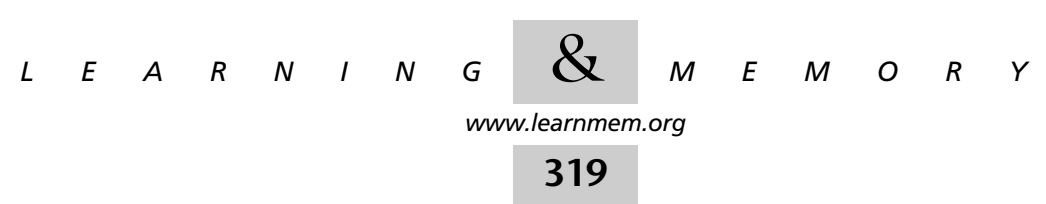


unimpaired group spent significantly more time near the person than the young $(P=0.015)$ and age-impaired $(P=0.0095)$ groups (Fig. 4).

\section{Curiosity Test}

The analysis of time spent exploring the toys in the test room revealed a significant interaction between age and retest $[\mathrm{F}(1,26)=4.25, P=0.049]$. The time spent exploring the objects increased for the young dogs and decreased for the old dogs. No significant effects were obtained for the frequency of sniffing the objects.

Taking into account cognitive status, a significant main effect of group was obtained for amount of time spent in contact with the objects $[\mathrm{F}(2,27)=3.89, P=0.033]$. This was a result of the young dogs spending significantly more time in contact with the objects than the age-impaired group $(P=0.027)$.

\section{Silhouette Test}

The analysis of sniffing the head region of the silhouette revealed a significant main effect of retest $[\mathrm{F}(1,26)=4.72$, $P=0.039]$. The interaction between sex and retest was also significant $[\mathrm{F}(1,26)=6.98, P=0.014]$, revealing that sniffing decreased from silhouette test 1 to silhouette test 2 in males only. The analysis of sniffing in the rear region revealed a significant effect of age $[F(1,26)=8.71$, $P=0.0066]$. Young dogs sniffed more often than aged dogs.

Cognitive status was related to the animals' response to the silhouette. The analysis of sniffing the head region revealed a significant main effect of retest $[F(1,27)=4.73$, $P=0.039]$. The interaction between group and retest was significant at the 0.1 level $[\mathrm{F}(2,27)=2.80, P=0.078]$. The young and age-unimpaired dogs showed less sniffing of the

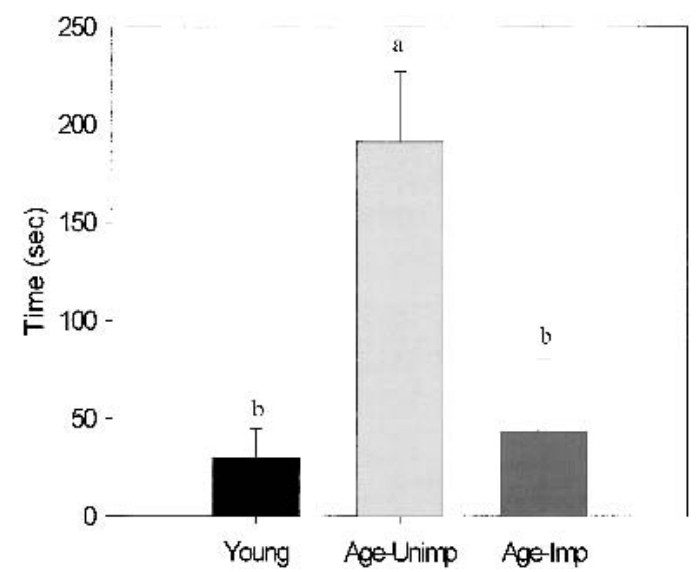

Figure 4 Time in seconds that the dogs spent sitting or standing beside the person in the human interaction test. The age-unimpaired dogs spent significantly more time close to the person than the age-impaired $(P=0.009)$ and young dogs $(P=0.015)$. "a" is significantly different from " $b$ ". Error bars represent standard errors of the mean. head region from silhouette test 1 to test 2 , while the ageimpaired dogs showed increased sniffing.

\section{Model Dog Test}

The analysis of the amount of time spent sniffing the model dog resulted in significant main effects of age $[\mathrm{F}(1,26)=15.65, P=0.00059]$ and retest $[\mathrm{F}(1,26)=11.55$, $P=0.0024]$. Young dogs spent more time sniffing the model than aged dogs, and sniffing time decreased from model dog test 1 to model dog test 2 .

The analysis involving cognitive status revealed significant main effects of group $[\mathrm{F}(2,27)=6.18, P=0.0066]$ and retest $[\mathrm{F}(1,27)=8.38, P=0.0078]$. The young dogs spent significantly more time sniffing the model dog than the ageunimpaired $(P=0.017)$ and age-impaired $(P=0.0082)$ dogs. Sniffing of the model dog was lower during test 2 .

\section{Activity Patterns}

To obtain a qualitative assessment of behavior, the activity patterns were examined. Each dog exhibited a characteristic idiosyncratic pattern of activity, which was similar with different types of tests. Thus, some dogs showed frequent jumping in every test, while others showed none. Some dogs urinated frequently while others rarely did. The young and age-unimpaired dogs' path of movements was modified when different stimuli were placed in the test room. The movements of the age-impaired dogs did not change with the various stimuli. These differences are illustrated in Figure 5 .

\section{Test-Retest Reliability}

To determine the test-retest reliability of the measures, correlation coefficients were determined for each of the measures between the two sessions of the same test for all animals. The results shown in Table 1 illustrate that there were positive correlations for every measure and all but two were significant at the 0.05 level.

\section{Intra-Rater Reliability}

The procedures developed used direct observation to sample from a range of behaviors (locomotion, rearing, inactivity, etc.) rather than using automated methods that do not distinguish between the different behaviors, that is, locomotion from rearing. To establish reliability of the measurement procedure, the same person (C.T.S.) analyzed each human interaction test session twice at an 8-month interval. The results shown in Table 2 indicate that there is a high degree of consistency and reliability in the behavioral measures when the same person watches the same test session twice at an 8-month interval.

\section{DISCUSSION}

The present experiment demonstrates first that exploratory behavior and locomotion are at least partially distinct in

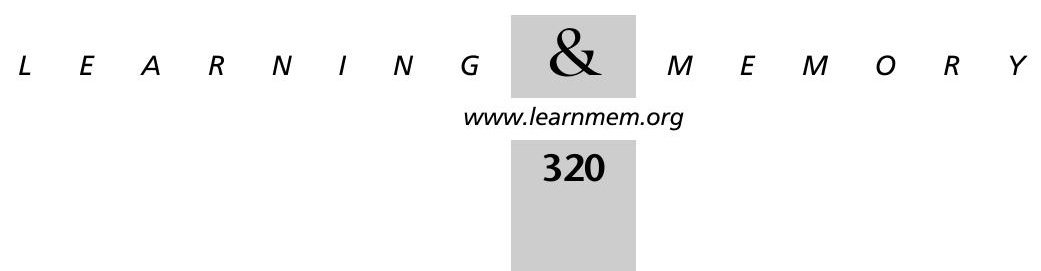



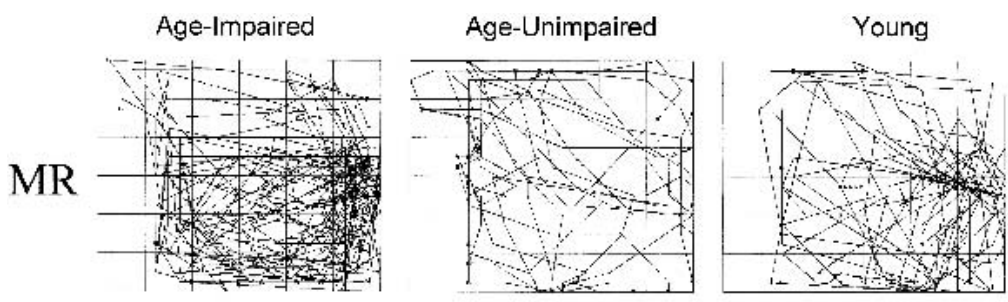

HI
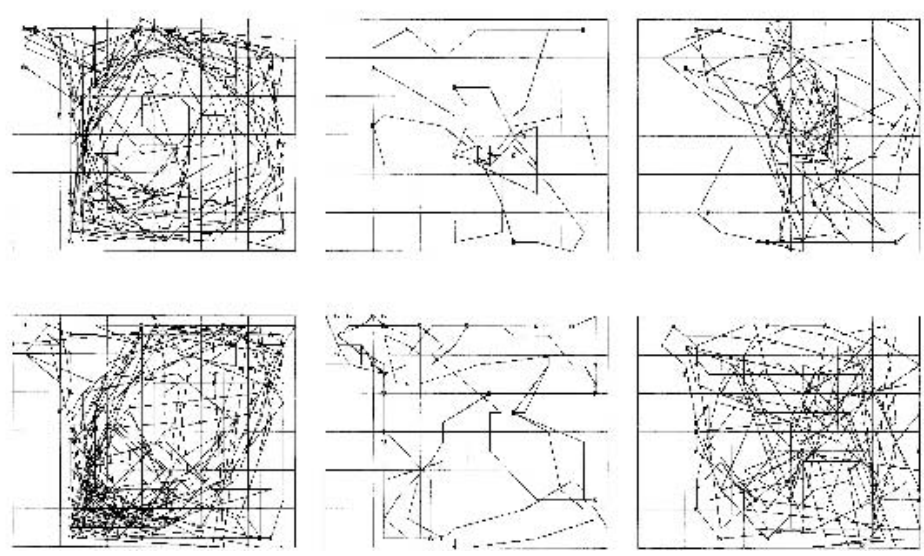

Figure 5 Tracings of the movement patterns of the dogs in the test room. The activity patterns of the age-impaired dogs did not change with the different tests. This group showed the same pattern regardless of stimuli present. The young and ageunimpaired dogs modified their behavior according to the test situation. MR, mirror test; $\mathrm{HI}$, human interaction test; $\mathrm{CU}$, curiosity test.

dogs and second, that both locomotion and exploratory behavior vary as a function of age and level of cognitive function, independently of test environment.

\section{Locomotion}

When age was considered independently of level of cognitive function, we found no effect of age on locomotion, consistent with our previous findings (Head and Milgram 1992; Head et al. 1997). However, the aged dogs showed extensive variability. When the aged dogs were divided into cognitively impaired and unimpaired groups, locomotion was lowest in the age-unimpaired dogs compared to the young dogs and age-impaired dogs. These findings support a link between cognitive impairment and behavioral activity.

An age-dependent decrease in behavioral activity is widely assumed to provide an index of canine cognitive dysfunction (Cummings et al. 1996; Ruehl and Hart 1998). The results of the present study suggest a more complex relationship. Age-unimpaired dogs exhibited lower levels of activity than young dogs, but the most severely impaired aged dogs often showed hyperactivity. However, when we consider the human literature, this finding is not surprising. Hyperactivity is often observed in dementia as well as other disorders such as attention deficit disorder and autism (Snowden et al. 1996; Hope et al. 1997; Rubia et al. 1998;
Pliszka et al. 2000; Castellanos et al. 2001). As such, increased activity could be one manifestation of the neurodegenerative changes that contribute to cognitive impairment.

Increased activity may result from degeneration of behavioral control mechanisms in the prefrontal cortical-striatal-pallidal circuitry. A disruption in this circuit may release the normal inhibitory controls on behavior that allow for appropriate behavioral responses and can lead to the production of repetitive or stereotypical behaviors (Pierce and Courchesne 2001; Sakagami et al. 2001). The functional interconnection between the frontal lobes and cerebellum also implicates a role for the cerebellum in the maintenance of proper behavioral controls (Pierce and Courchesne 2001). Thus, the normal age-associated decline in physical activity produced by a general deterioration in endurance, strength, and coordination can be disrupted by pathology in the central nervous system that leads to a pathological increase in activity.

\section{Locomotion and Exploration}

We operationally defined responses to novel objects (physical contacts and sniffing of objects) in the curiosity test as exploratory behavior. The scores on this measure were independent of locomotion. The age-impaired dogs were very active but almost completely ignored the various toys present. Young dogs contacted the toys significantly more than either of the aged groups. The age-unimpaired dogs played with the toys to a

\begin{tabular}{|c|c|c|}
\hline Test & Behavioral measure & Correlation (r) \\
\hline \multirow[t]{8}{*}{ Open field } & Locomotion & $0.85^{*}$ \\
\hline & Urination & $0.60^{*}$ \\
\hline & Sniffing & $0.31 *$ \\
\hline & Grooming & 0.06 \\
\hline & Inactivity & $0.64 *$ \\
\hline & Rearing & $0.75^{*}$ \\
\hline & Vocalization & $0.38^{*}$ \\
\hline & Jumping & $1.00^{*}$ \\
\hline \multirow[t]{2}{*}{ Mirror test } & Image interaction & $0.49 *$ \\
\hline & Image sniffing & $0.63^{*}$ \\
\hline \multirow[t]{3}{*}{ Human interaction } & Sniffing person & $0.69 *$ \\
\hline & Contacting person & 0.65 \\
\hline & Beside person & $0.71 *$ \\
\hline \multirow[t]{2}{*}{ Curiosity test } & Contacting objects & $0.57^{*}$ \\
\hline & Sniffing objects & $0.82 *$ \\
\hline \multirow[t]{2}{*}{ Silhouette test } & Sniffing head region & $0.33^{*}$ \\
\hline & Sniffing rear region & 0.28 \\
\hline Model dog test & Sniffing model dog & $0.69 *$ \\
\hline
\end{tabular}

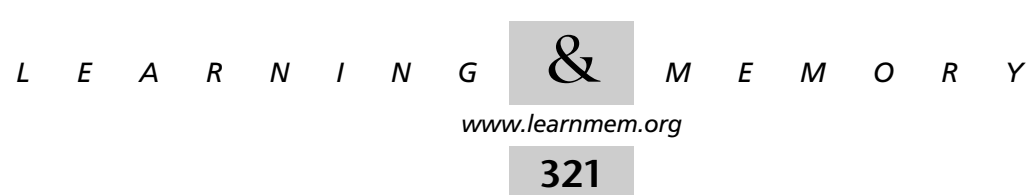


Table 2. Intra-Rater Reliability of All Measures in the Human Interaction Test

\begin{tabular}{lcc}
\hline $\begin{array}{l}\text { Behavioral measure in } \\
\text { human interaction test }\end{array}$ & $\begin{array}{c}\text { Test } 1 \text { redo } \\
\text { correlations }(\mathrm{r})\end{array}$ & $\begin{array}{c}\text { Test } 2 \text { redo } \\
\text { correlations }(\mathrm{r})\end{array}$ \\
\hline Locomotion & $0.99^{*}$ & $0.99^{*}$ \\
Urination & $0.99^{*}$ & $0.99^{*}$ \\
Sniffing & $0.96^{*}$ & $0.90^{*}$ \\
Grooming & $0.97^{*}$ & $0.98^{*}$ \\
Inactivity & $0.95^{*}$ & $0.99^{*}$ \\
Rearing & $0.83^{*}$ & $0.88^{*}$ \\
Vocalization & $0.99^{*}$ & $0.71^{*}$ \\
Jumping & $\mathrm{n} / \mathrm{a}$ & $0.99^{*}$ \\
Sniffing person & $0.95^{*}$ & $0.89^{*}$ \\
Contacting person & $0.99^{*}$ & $0.99^{*}$ \\
Beside person & $0.96^{*}$ & $0.99^{*}$ \\
\hline $\mathrm{n}=30 ;{ }^{*} P<0.05$ (two-tailed). &
\end{tabular}

lesser extent, suggesting that the response to novelty declines with age but that normal aged dogs still like to play.

\section{Behavioral Profiles}

Taking all of the tests into consideration, young and aged dogs exhibited distinct behavioral profiles. Young dogs, in general, show greater responsiveness to any type of modification of the test environment than aged dogs. The young dogs spent more time in physical contact with the person and the objects. The young dogs showed greater sniffing of the silhouette and model dog. Finally, the young dogs spent more time reacting to the mirror reflection than the unimpaired aged dogs.

Distinct profiles also existed for the age-unimpaired and age-impaired animals. The age-unimpaired dogs spent the most time beside the person and the least time reacting to the reflection. They were moderate in the time spent in contact with the objects and sniffing the model dog and silhouette. The behavioral profile of the age-unimpaired dogs was similar to that of the young dogs in that they responded to changes in the test environment but to a lesser extent. The unimpaired group displayed appropriate social responses to the human and artificial conspecifics. These findings indicate that with normal aging similar types of responses to various stimuli are present, just diminished. Aged animals have more experience with stimuli and novelty, and a type of desensitization process may occur over the lifespan so that although unimpaired aged animals still respond appropriately, the responses are not as great as those of a young animal that is still learning and exploring.

The age-impaired dogs were generally unresponsive to the person, the objects, the silhouette, and the model dog. The age-impaired dogs' activity patterns were unchanged by modifications in the stimuli present in the test environment. The age-impaired dogs exhibited undirected, random activity that tends to be stereotypical in that it does not change in different situations. This group of dogs just walked around the testing room without reacting to the assortment of novel stimuli in the room. The lack of exploratory behavior exhibited by the age-impaired group may reflect a specific deficit in the frontal lobes or cerebellum, as both of these structures have been implicated in responding to novel stimuli and are functionally interconnected (Daffner et al. 1998; Pierce and Courchesne 2001). Repetitive or stereotypical behaviors are also correlated with cerebellar and frontal lobe measures (Pierce and Courchesne 2001).

This group spent the greatest amount of time reacting to the reflection in the mirror. These dogs would jump at, appear to play with, bark at, and turn and try to catch the dog in the reflection. Some dogs would look behind the mirror in an attempt to find the other dog. The unimpaired dogs, in contrast, showed a rapid habituation. The mirror test is often used as a test of self-recognition in primates (Boysen and Himes 1999) and Alzheimer's patients (Biringer and Anderson 1992; Grewal 1994; Bologna and Camp 1997). Severe degrees of dementia in Alzheimer's disease (GDS > 6) are associated with the inability of patients to recognize themselves. This is one type of misidentification syndrome reported in Alzheimer's patients (Mendez et al. 1992). Misidentification symptoms in Alzheimer's disease may be associated with an accentuated degeneration of the right frontal lobe (Biringer et al. 1989; Forstl et al. 1991; Mendez et al. 1992). The same mechanisms may be disrupted in the dog. The dogs that exhibited the unique reactions to the mirror image are the same ones that showed excessive levels of locomotion. A disruption in the frontal lobe circuitry could produce both effects as well as the lack of response to the novel objects. The frontal lobe in the dog is the site of the earliest and most consistent signs of amyloid deposition with age, and disruption in the behavioral mechanisms mediated by the frontal lobe is consistent with the observations reported here (Head et al. 2000).

\section{Social Responsiveness}

The human interaction, silhouette, and model dog tests were designed to examine various aspects of the social behavior of the dogs. The human interaction test was designed to examine the unique social relationship that forms when dogs interact with humans. The silhouette and model dog tests were designed to measure what component stimuli of a conspecific elicit responses. Sniffing of the anal region is a common reaction to meeting a new $\mathrm{dog}$, and preference for the facial region is a purely social greeting (Fox and Weisman 1969). The young dogs were the most socially responsive group. They sought physical contact from the person and sniffed the silhouette and model dog to a greater extent than the aged dogs. The age-unimpaired dogs also showed more human interaction, and sniffed the silhouette more often than the age-impaired group. The age-impaired dogs ignored the person and model dog, and showed an

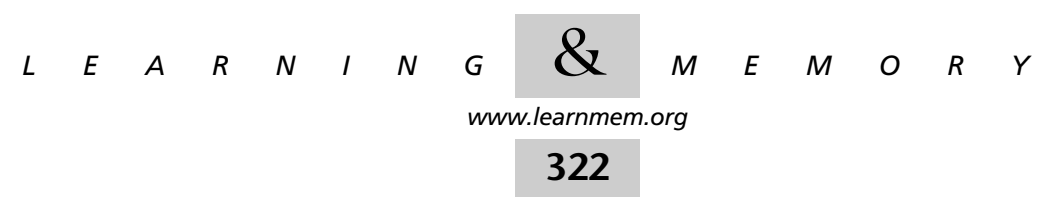


increase in sniffing the silhouette between tests, the opposite result from the young and age-unimpaired group. The age-impaired dogs appear to have a deficit in social responding and decreased affection consistent with observations of geriatric pet dogs (Ruehl and Hart 1998). Disruption of the behavioral inhibitory mechanisms of the frontal lobes could be responsible for changes in social behavior.

\section{Conclusions}

We can distinguish three different types of behavioral activity in dogs: directed, undirected, and stereotypical. Directed activity is oriented toward a goal, that is, exploration of a room, object, or person. Undirected activity is random activity. Stereotypical activity is an organized type of undirected activity, repetitive patterns of behavior. Undirected and stereotypical behaviors are indicative of functional deficiencies in brain systems. Cognitively impaired dogs show more undirected and stereotypical behavior. Brain pathology may disrupt normal control of behavior. Disruption of the frontal or cerebellar regions can release the normal inhibitory controls on behavior leading to nonfunctional repetitive behavior instead of normal directed exploration. It is likely that a dysfunction of the prefrontal cortical-striatalpallidal circuitry is involved in the production of the abnormal responses observed in our cognitively impaired aged dogs.

\section{MATERIALS AND METHODS}

\section{Design}

Activity tests were conducted every second day in the following sequence: open field test, mirror test, human interaction test, curiosity test, silhouette test, and model dog test. Each test was given twice. A total of 12 tests was administered for each dog. Dogs were administered a delayed nonmatching to position task prior to activity testing and a size discrimination task following activity assessments.

\section{Subjects}

The study was performed using 7 young ( 4 males; 3 females) and 23 aged ( 8 males; 15 females) beagles from the colony at the University of Toronto. The aged dogs ranged in age from 9 to 15 , and the young dogs ranged from 2 to 4 years old. The dogs were individually housed in $1.07 \times 1.22 \mathrm{~m}$ pens and maintained on a $12 \mathrm{~L}: 12 \mathrm{D}$ cycle. Pens were washed daily between 8:00 am and 10:00 am, during which time the animals were exercised for 15 minutes. Water was available ad libitum. Dogs were fed approximately 2 cups of standard laboratory chow daily. All dogs were in good health at the time of behavioral testing.

\section{Behavioral Test Procedures}

\section{Cognitive Testing Procedures}

The test apparatus, as described previously (Milgram et al. 1994) consisted of a wooden box $0.609 \mathrm{~m} \times 1.15 \mathrm{~m} \times 1.08 \mathrm{~m}$, with vertical aluminum bars at the front, a moveable Plexiglas tray with three food wells, a small overhead incandescent light, and a wooden partition containing a one-way mirror and hinged door to separate the investigator from the animal. The heights of the vertical bars can be adjusted for each dog to allow access to the food placed in the tray wells. A dedicated computer program was used for controlling all timing procedures, for specifying the location of the correct choice, and for capturing data. The test sessions were once daily.

Cognitive characterization was based on the dogs' performance on two neuropsychological tests, a delayed nonmatching to position (DNMP) task and a size discrimination learning task (Head et al. 1995,1998; Adams et al. 2000a,b). Aged dogs were classified as impaired if the combined error score on the size and DNMP tasks was greater than two standard deviations from the mean score of the young dogs.

The size discrimination task used two objects that differed only in size. The tray was presented with the two objects placed over the lateral wells. The dog must displace the object that is associated with the reward, and the choice is based only on the size of the object. The dogs were given ten trials per day with a $30 \mathrm{sec}$ interval between trials. Dogs were tested daily until they passed. The learning measure used was errors made until the criterion was reached.

The DNMP task is more complex. Each trial of the task involves two components. The first is the sample phase, in which the dog was presented with a sample object in one of two lateral wells on the tray. The sample object has a food reward placed beneath it. The tray was then removed for a delay of $10 \mathrm{sec}$. After the delay, the tray was presented a second time with the sample object covering the same well and a new identical object covering the second well. The dog was required to go to the object in the new location to receive the food reward. The dog was considered to have made an incorrect choice if it came into contact with the sample object that had previously been presented. The dogs were given ten trials per day with a 60 -sec interval between trials. When the dog passed the task at the 10-sec delay, it moved on to a 20 -sec delay and then a 30 -sec delay. The longer delays make the task more difficult. The memory measure used was errors made to reach criterion for each delay.

\section{General Activity Testing Procedures}

All testing took place in a $3.66 \times 3.66 \mathrm{~m}$ room containing a sink and cupboards. There were two large Plexiglas windows and two doors in the walls of the room. The floor was marked into 32 squares 61 $\times 61 \mathrm{~cm}$ with black electrical tape to facilitate localization of the animal's position (two squares were located under the sink). The floor and base of the walls and cupboards were cleaned with a detergent solution prior to each test to prevent odor cues from other dogs affecting the animal's behavior. All windows were covered with black plastic excluding a small area for observing and videotaping the dogs. Test sessions were $10 \mathrm{~min}$ in duration. The dog was released into the room through one of the doors, and an observer located outside of one window used a video camera to record behavior. To minimize variability and bias, the same person (C.T.S.) performed all of the behavioral observations. The videotapes were analyzed with a dedicated computer program (see Head and Milgram 1992) that provided quantitative measures of locomotion, directed sniffing, urination, inactivity, grooming, rearing, vocalization, and jumping. The measures recorded were total distance for locomotion, total time for grooming and inactivity, and the frequency of occurrence for sniffing, urination, rearing, vocalizing, and jumping.

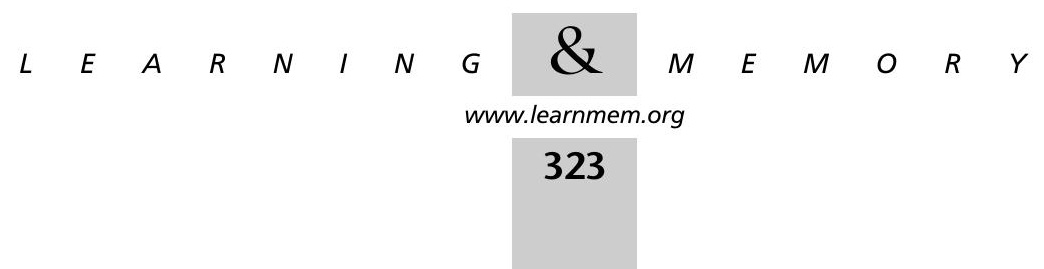




\section{Open Field Test}

For the open field test, a profile of the animal's total behavior pattern in an empty room over a 10 -min period was obtained.

\section{Mirror Test}

A mirror was placed against one wall of the test room. The mirror was secured to the wall and cleaned between tests. Additional behavioral measures for this test were time spent reacting to the reflection and frequency of sniffing the reflection. The mirror test was originally developed by Gallup $(1968,1970)$ as a test of selfrecognition in primates. We examined the reaction of each dog to the presence of the mirror.

\section{Human Interaction Test}

This test assessed the reaction of the dog to the presence of a person and has previously been described (Head et al. 1997). A person sat in the center of the room and was instructed to sit on the floor at a fixed position and avoid responding to the dog. The additional behavioral measures were the total amount of time of physical contact, total amount of time standing or sitting beside the person without making contact, and frequency of sniffing the person.

\section{Curiosity Test}

Seven distinct objects were placed in fixed positions in the room. The objects were cleaned with a detergent solution before each test. The objects included a hanging tennis ball, a knotted chew rope for dogs, a large plush squeaky ball, a rubber squeaky fire hydrant, a plush squeaky gerbil, a plush squeaky jack, and a hanging purple plush dinosaur. All of the objects were commercially available from the local pet store. The behavioral measures taken include the total amount of time in physical contact with the objects and frequency of sniffing the objects. Each dog was allowed to freely examine the objects to assess its' reaction to novel objects.

\section{Silhouette Test}

A black, laminated cardboard figure of a dog was secured to one wall. The silhouette was cleaned between tests. The behavioral measures included frequency of sniffing the head region and frequency of sniffing the rear region of the silhouette. This test was intended to provide measures of social responsiveness to a conspecific (Fox and Weisman 1969).

\section{Model Dog Test}

A life-size sandcast model of a golden retriever was placed in a fixed position in the center of the room. The model was cleaned between tests. The behavioral measures included time spent sniffing the model dog. This test was intended to provide measures of social responsiveness to a conspecific.

\section{Data Analysis}

The data were analyzed using a three-way analysis of variance (ANOVA) with age and sex as between-subject factors and retest as a within-subject factor. Tukey's HSD post hoc test was used for multiple comparisons. A subsequent analysis examined the effect of cognitive status of the aged dogs on behavior using a two-way ANOVA with group (young, age-impaired, age-unimpaired) as a between-subject factor and retest as a within-subject factor, because each test was performed twice. Tukey's HSD post hoc test was used to compare the three groups of dogs when a significant main effect of group was obtained. Test-retest and intra-rater reliability were assessed using Pearson product correlation coefficients.

\section{ACKNOWLEDGMENTS}

This research was supported by the National Institute of Aging (NIA AG12694) and by a grant from Hill's Pet Nutrition, Topeka, Kansas.

The publication costs of this article were defrayed in part by payment of page charges. This article must therefore be hereby marked "advertisement" in accordance with 18 USC section 1734 solely to indicate this fact.

\section{REFERENCES}

Adams, B., Chan, A., Callahan, H., and Milgram, N.W. 2000b. The canine as a model of human cognitive aging: Recent developments. Prog. Neuropsychopharmacol Biol. Psychiatry. 24: 675-692.

Adams, B., Chan, A., Callahan, H., Siwak, C., Tapp, D., Ikeda-Douglas, C., Atkinson, P., Head, E., Cotman, C.W., and Milgram, N.W. 2000a. Use of a delayed non-matching to position task to model age-dependent cognitive decline in the dog. Behav. Brain. Res. 108: 47-56.

Archer, J. and Birke, L.I.A. 1983. Methods of studying exploration. In Exploration in animals and bumans, pp. 27-39. Van Nostrand Reinhold (UK), Great Britain.

Berlyne, D.E. 1950. Novelty and curiosity as determinants of exploratory behavior. Br. J. Psychol. 41: 68-80

Berlyne, D.E. 1955. The arousal and satiation of perceptual curiosity in the rat. J. Comp. Physiol. Psychol. 48: 238-246.

Berlyne, D.E. 1960. Exploratory Behavior: Locomotor Exploration. In Conflict, arousal, and curiosity, pp. 104-135. McGraw Hill, New York.

Biringer, F., Anderson, J.R., and Strubel, D. 1989. Self-recognition in senile dementia. Exp. Aging Res. 14: 177-180.

Biringer, F. and Anderson, J.R. 1992. Self-recognition in Alzheimer's disease: A mirror and video study. J. Gerontology. 47: P385-P388.

Bologna, S.M. and Camp, C.J. 1997. Covert versus overt self-recognition in late stage Alzheimer's disease. J. Int. Neuropsychol. Soc. 3: 195-198.

Boysen, S.T. and Himes, G.T. 1999. Current issues and emerging theories in animal cognition. Annu. Rev. Psychol. 50: 683-705.

Brennan, M.J., Blizard, D.A., and Quartermain, D. 1982. Amelioration of an age-related deficit in exploratory behavior by preexposure to the test environment. Behav. Neural. Biol. 34: 55-62.

Castellanos, F.X., Giedd, J.N., Berquin, P.C., Walter, J.M., Sharp, W., Tran, T., Vaituzis, C., Blumenthal, J.D., Nelson, J., Bastain, T.M., et al. 2001. Quantitative brain magnetic resonance imaging in girls with attention-deficit/hyperactivity disorder. Arch. Gen. Psychiatry. 58: 289-295.

Cummings, B.J., Head, E., Ruehl, W., Milgram, N.W., and Cotman, C.W. 1996. The canine as an animal model of human aging and dementia Neurobiol. Aging. 17: 259-268.

Daffner, K.R., Mesulam, M.M., Scinto, L.F.M., Cohen, L.G., Kennedy, B.P., West, W.C., and Holcomb, P.J. 1998. Regulation of attention to novel stimuli by frontal lobes: An event related potential study. Neuroreport. 9: 787-791.

Forstl, H., Burns, A., Jacoby, R., and Levy R. 1991. Neuroanatomical correlates of clinical misidentification and misperception in senile dementia of the Alzheimer type. J. Clin. Psychiatry. 52: 268-271.

Fox, M.W. and Weisman, R. 1969. Development of responsiveness to a social releaser in the dog: Effects of age and hunger. Dev. Psychobiol. 2: 277-280.

Furchtgott, E., Wechkin, S., and Dees, J.W. 1961. Open-field exploration as a function of age. J. Comp. Physiol. Psychol. 54: 386-388.

Gage, F.H., Dunnett, S.B., and Bjorklund, A. 1984. Spatial learning and motor deficits in aged rats. Neurobiol. Aging. 5: 43-48.

Gallagher, M. and Burwell, R.D. 1989. Relationship of age-related decline across several behavioral domains. Neurobiol. Aging. 10: 691-708.

Gallup, G. Jr. 1968. Mirror-image stimulation. Psychol. Bull. 70: 782-793.

Gallup, G. Jr. 1970. Chimpanzees: Self-recognition. Science. 167: 86-87.

Grewal, R.P. 1994. Self-recognition in dementia of the Alzheimer type. Percept. Mot. Skills. 79: 1009-1010.

Handa, R.J., George, M., Gordon, B.H., Campbell, D.B., and Lorens, S.A.

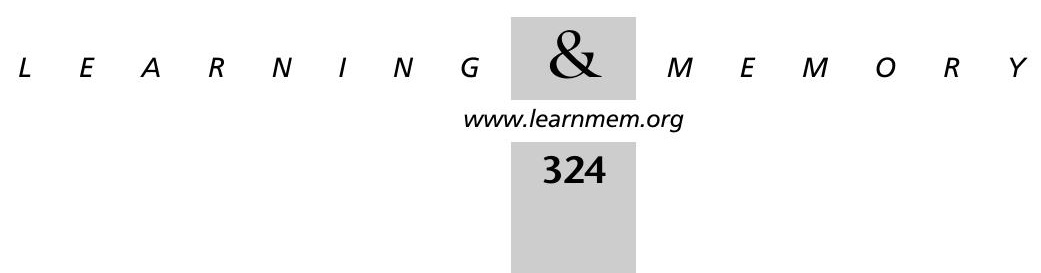


1996. Responses to novelty stress in female F344 rats: Effects of age and d-fenfluramine treatment. Pharmacol. Biochem. Behav. 53: 641-647.

Head, E., Callahan, H., Cummings, B.J., Cotman, C.W., Ruehl, W.W., Muggenburg, B.A., and Milgram, N.W. 1997. Open field activity and human interaction as a function of age and breed in dogs. Physio.l Behav. 62: 963-971.

Head, E., Callahan, H., Muggenburg, B.A., Cotman, C.W., and Milgram, N.W. 1998. Visual-discrimination learning ability and $\beta$-amyloid accumulation in the dog. Neurobiol. Aging. 19: 415-425.

Head, E., McCleary, R., Hahn, F.F., Milgram, N.W., and Cotman, C.W. 2000. Region-specific age at onset of $\beta$-amyloid in dogs. Neurobiol. Aging. 21: 89-96.

Head, E., Mehta, R., Hartley, J., Kameka, M., Cummings, B.J., Cotman, C.W., Ruehl, W.W., and Milgram, N.W. 1995. Spatial learning and memory as a function of age in the dog. Behav. Neurosci. 109: 851-858.

Head, E. and Milgram, N.W. 1992. Changes in spontaneous behavior in the dog following oral administration of L-Deprenyl. Pharmacol. Biochem. Behav. 43: 749-757.

Hope, T., Keene, J., Fairburn, C., McShane, R., and Jacoby, R. 1997. Behavior changes in dementia 2: Are there behavioral syndromes? Int. J. Geriatr. Psychiatry.12: 1074-1078.

Ingram, D.K. 1988. Key questions in developing biomarkers of aging. Exp. Gerontol. 23: 429-434.

Kelley, A.E., Cador, M., and Stinus, L. 1989. Exploration and its measurement: A psychopharmacological perspective. In Neuromethods 13: Psychopharmacology. (eds A.A. Boulton, G.B. Baker, and A.J. Greenshaw), pp. 95-144. Humana Press, Clifton, New Jersey.

Leyland, M., Robbins, T., and Iversen S.D. 1976. Locomotor activity and exploration: The use of traditional manipulators to dissociate these two behaviors in the rat. Anim. Learning. Behav. 4: 261-265.

Mendez, M.F., Martin, R.J., Smyth, K.A., and Whitehouse, P.J. 1992.
Disturbances of person identification in Alzheimer's disease: A retrospective study. J. Nerv. Ment. Dis. 180: 94-96.

Milgram, N.W., Head, E., Weiner, E., and Thomas, E. 1994. Cognitive functions and aging in the dog: Acquisition of nonspatial visual tasks. Behav. Neurosci. 108: 57-68.

Montgomery, K.C. 1953. The effect of activity deprivation upon exploratory behavior. J. Comp. Physiol. Psychol. 46: 438-441.

Pierce, K. and Courchesne, E. 2001. Evidence for a cerebellar role in reduced exploration and stereotyped behavior in autism. Biol. Psychiatry 49: 655-664.

Pliszka, S.R., Liotti, M., and Woldorff, M.G. 2000. Inhibitory control in children with attention-deficit/hyperactivity disorder: Event-related potentials identify the processing component and timing of an impaired right-frontal response-inhibition mechanism. Biol. Psychiatry. 48: 238-246.

Rowe, W.B., Spreekmeester, E., Meaney, M.J., Quirion, R., and Rochford, J. 1998. Reactivity to novelty in cognitively-impaired and cognitively-unimpaired aged rats and young rats. Neuroscience.83: 669-680.

Rubia, K., Oosterlaan, J., Sergeant, J.A., Brandeis, D., and Leeuwen, T.V. 1998. Inhibitory dysfunction in hyperactive boys. Behav. Brain. Res. 94: 25-32.

Ruehl, W.W. and Hart, B.J. 1998. Canine cognitive dysfunction. In Psychopharmacology of animal behavior disorders (eds. N. Dodman and L. Shuster), Ch. 13. pp. 283-304. Blackwell Scientific Publications, Malden, MA

Sakagami, M., Tsutsui, K., Lauwereyns, J., Koizumi, M., Kobayashi, S., and Hikosaka, O. 2001. A code for behavioral inhibition on the basis of color, but not motion, in ventrolateral prefrontal cortex of macaque monkey. .J Neurosci.. 21: 4801-4808.

Snowden, J.S., Neary, D., and Mann, D.M.A. 1996. Fronto-temporal dementia. In Fronto-temporal lobar degeneration, pp. 9-41. Churchill Livingstone, New York.

Williams, C.D., Carr, R.M., and Peterson, H.W. 1966. Maze exploration in young rats of four ages. J. Genet. Psychol.. 109: 241-247. 


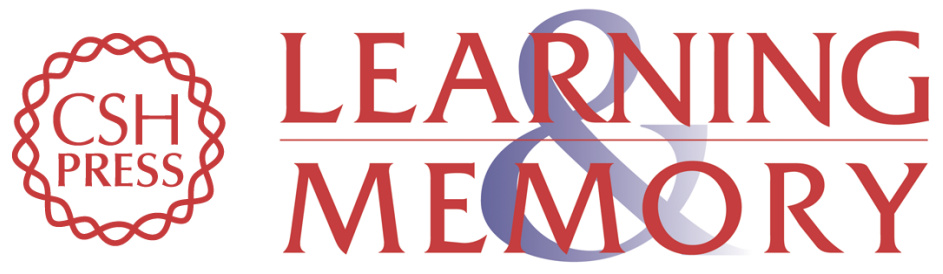

\section{Effect of Age and Level of Cognitive Function on Spontaneous and Exploratory Behaviors in the Beagle Dog}

Christina T. Siwak, P. Dwight Tapp and Norton W. Milgram

Learn. Mem. 2001, 8:

Access the most recent version at doi:10.1101//m.41701

References This article cites 36 articles, 2 of which can be accessed free at:

http://learnmem.cshlp.org/content/8/6/317.full.html\#ref-list-1

License

Email Alerting Receive free email alerts when new articles cite this article - sign up in the box at the Service top right corner of the article or click here. 